\title{
The Cultural Impact of Information Systems - Through the Eyes of Hofstede - A Critical Journey
}

\author{
Michael Jones \\ University of Wollongong, \\ Wollongong, Australia
}

\author{
Irit Alony \\ Central Queensland University, \\ Rockhampton, Australia
}

mjones@uow.edu.au

i.alony@cqu.edu.au

\begin{abstract}
With the increasing levels of multiculturalism in today's business and the proliferation and essentiality of information systems, development and management of IS needs to be considered in light of the cultural factors which impact upon its utility. Hofstede's work on culture is the most widely cited in existence. His observations and analysis provide scholars and practitioners a valuable insight into the dynamics of cross-cultural relationships. However, such a groundbreaking body of work does not escape criticism. Hofstede has been dogged by academics discrediting his work in part or whole. Nonetheless, far more scholars exist who support Hofstede than those that don't. Most quote Hofstede's work with unabashed confidence, many including his findings as absolute assumptions.

This paper takes a critical look at Hofstede's work and applies his findings to the practical needs of information systems. The paper finds support for the dimensions promoted by Hofstede in regard to information systems, but recommends continued research to provide greater clarity and continued applicability of his espoused dimensions.
\end{abstract}

Keywords: Culture, Information Systems, Hofstede, Cultural Dimensions, Cross-Cultural Research.

\section{Introduction}

"Undoubtedly, the most significant cross-cultural study of work-related values is the one carried out by Hofstede" (Bhagat \& McQuaid, 1982)

Much interest has been placed on culture in business in the last two decades, and with growing national diversity in today's business, culture remains an important dimension. The study of the field began in earnest with the work of Hofstede with his landmark study of IBM (Hofstede 1980), and with Peters and Waterman who started the organisation culture sensation with "In

Material published as part of this publication, either on-line or in print, is copyrighted by the Informing Science Institute. Permission to make digital or paper copy of part or all of these works for personal or classroom use is granted without fee provided that the copies are not made or distributed for profit or commercial advantage AND that copies 1) bear this notice in full and 2) give the full citation on the first page. It is permissible to abstract these works so long as credit is given. To copy in all other cases or to republish or to post on a server or to redistribute to lists requires specific permission and payment of a fee. Contact Publisher@InformingScience.org to request redistribution permission.
Search of Excellence" (Peters \&

Waterman 1982). Preceding these studies however, was the work of Bartels (1967) who was one of the first to relate the importance of culture, illustrating the concept in decision-making and business ethics. Bartels identifies several criteria for the identification of cultural differences, including: 
- Law;

- Respect for individuality;

- Nature of Power and Authority;

- Rights of Property;

- Concept of Deity;

- Relation of Individual to State;

- National Identity and Loyalty;

- Values, Customs and Mores;

Culture is important for many aspects of business life especially with regard to the design, development and management of Information Systems (IS) protocols and infrastructure (Myers and Tan 2002). Kumar and Bjom-Andersen (1990) claim that design and management choices in IS are the result of individual values, and these values are a product of socio-cultural background:

The designers' values are the product of the professional, social, and organizational context within which they are held, and of the individual's background and education. Accordingly, their design choices are strongly influenced by their socio-cultural environment (Kumar and Bjorn-Anderson 1990, p. 530)

Straub, Loch, Evaristo, Karahanna and Strite (2002, p. 13) discuss the clear lack of cross-cultural attention that has been paid to IS: "Despite its universally recognized importance, the effect of cultural factors on IT outcomes has received limited attention from information systems (IS) researchers. As a result cross-cultural information systems research, in general, remains in a state of infancy".

When people interface with information technology through IS, human cultural values must be taken into consideration. Cross-cultural research has had most value therefore when it has been able to provide substance to modern management practices and techniques dealing with IS. Many cross-cultural researchers, including Hofstede, have been criticised for not providing this valuable guiding intelligence. Michael and College (1997) state that literature tends to lack specificity and is expressed in broad behavioural terms. This paper concentrates on the research provided by Hofstede, not on its applicability, and brings this area of study into the arena of information systems proving IS scholars additional insight.

\section{What is Culture?}

We begin our discussion on culture with a definition. The quantity of cultural definitions expounded by learned researchers are too numerous to count, each one having a relevant claim to a meaningful understanding of the terms of culture. Olie discusses over 164 different definitions for culture collected up until 1951 (1995, p. 128). Hofstede himself also provides equivocal definitions. "A collective programming of the mind which distinguishes one group from another" (Hofstede, 1980, p. 25). "Mental programming ... patterns of thinking and feeling and potential acting" (Hofstede 1991a, p. 4).

A key term in these definitions is the word 'programming'. Culture is not something that is easily acquired it is a slow process of growing into a society. It includes:

- learning values (dominant beliefs and attitudes),

- partaking of rituals (collective activities),

- modelling against heroes (role models), and

- understanding symbols (myths, legends, dress, jargon, lingo...) 
These ingredients of culture are acquired from birth. They are influenced by family, school, religion, workplace, friends, television, newspapers and books, and many other sources.

\section{Hofstede's Study}

Geert Hofstede's gargantuan research effort commencing in 1980 is the most celebrated of its kind (Bond 2002; Hofstede 1997). The study comprised 116,000 questionnaires, from which over 60,000 people responded from over 50 countries. Hofstede worked with IBM (at the time identified as Hermes) staff over the years 1967 to 1978 to obtain this research. From the data he obtained he provided a factor analysis of 32 questions in 40 countries. From this he identified four bipolar dimensions (Power Distance; Individualism/Collectivism; Uncertainty Avoidance; Masculinity/Feminity), which became the basis of his characterisations of culture for each country (d'Iribarne 1996, 33; Dorfman \& Howell 1988, 129; Hofstede 1980; Schneider \& Barsoux 1997, 79).

A subsequent study conducted by Hofstede and Bond (Hofstede. 1991a, 1991b; Hofstede \& Bond 1984, 1988) introduced a fifth element 'Confucian Dynamism' or 'Long/Short Term Orientation', which was an attempt to fit the uncertainty avoidance dimension into the Asian culture. Note: This dimension is not discussed in this paper.

Hofstede's research has had a remarkable effect on academics and practitioners alike. Hofstede's model has been instrumental in the implementation of many business systems, including: compensation practices; budget control practices; entrepreneurial behaviour; training design; conflict resolution; workgroup dynamics and performance; innovation; leadership styles; management control systems; participative management (Michael, 1997, p. 84; Smith, 1998, p. 62), and of course many other cross-cultural issues.

\section{Problems Associated with Cross-Cultural Research}

Cross-cultural research is not an easy task (Cavusgil \& Das, 1997). The researcher must overcome many additional factors not inherent in typical research tasks. Some of these factors are discussed below.

\section{Definition Problems}

Terms used in research instruments; particularly the word 'culture' itself is open to interpretation (Nasif, Al-Daeaj, Ebrahimi \& Thibodeaux, 1991, p. 82). As has been discussed there are more than 164 definitions for this one word alone (Olie, 1995, p. 128). Then when one considers other terminology used in the questionnaire these too become subject to interpretation. It can become a case of: is the question determining the culture, or the culture determining the question? Problems of translating questions and responses add to these difficulties (Henry, 1990, p. 32).

\section{Methodological Simplicity}

One error most researchers have in common, is that they are based on an ethnocentric pattern, and they represent a single timeframe only. These errors can provide bias, misinterpretation and inaccuracies (Lubrosky, 1959, p. 326; Nasif et al., 1991, pp. 83-84).

A final problem with methodological simplicity is the question of the researchers background, that is, research tends to be from only one discipline, a better foundation is for multi-disciplinary approach (sociology, psychology, political science, economics, anthropology, etc.) (Nasif et al., 1991, pp. 83-84). 


\section{Equivalency}

Equivalency can be divided into four dimensions: functional, conceptual, instrument and measurement equivalence (Cavusgil \& Das, 1997).

Functional equivalence assumes that a functional role in one country is the same in another (Hays, Anderson \& Revicki, 1993; Johnson, 1998, pp. 4-6; Nasif et al., 1991, pp. 83-84). For example considering the usage of bicycles in Australia and Vietnam, the two countries would perceive different uses. Australians would see the use as predominately recreational, while many Vietnamese would see it as an essential mode of transport (Cavusgil \& Das, 1997).

Conceptual equivalence regards the cultural utility of behavioural or attitudinal constructs. For instance, company loyalty in Asia may be seen as devotion to one's workplace and by following the rules, while in Australia it may be following instructions and not breaking the rules (Cavusgil \& Das, 1997).

Instrument equivalence and measurement equivalence regard the cross-cultural consistency of the research instrument, whether it is equally represented across the entire sample. This includes participant bias towards scaling. For example some cultures will tend not to provide extreme levels on a scaled question, while other cultures will tend to (Martin \& Frost 1996; Nasif et al., 1991). Language can also be problematic in this regard and can be overcome through the adoption of back-translation and multilingual panel analysis (Cavusgil \& Das, 1997).

Inadequate attention to these methodological constraints can affect the viability of cross-cultural research. It is therefore critical a researcher adopts as unbiased and unambiguous a research instrument as is practical. However, latitude should be granted to ensure both qualitative and quantitative examination, as was the case with Hofstede's $(1980,1998,2002)$ research. In this vein, application of the former method encourages the use of certain bias as a means of data acquisition.

\section{Hofstede's Findings and Relevance to IS}

As a result of his multi-nation study Hofstede devised four dimensions to characterise cross cultural differences. These, and their impact on IS, are discussed below.

\section{Power Distance (PD)}

PD has to do with the degree to which unequal distribution of power and wealth are tolerated. This can be determined by the level of hierarchy in workplaces and distance between social strata. Malaysia ranks low on Hofstede's scale showing that they hold large distances between ranks in an organisation; communications are likely to be through the command chain rather than direct. Israel is at the other end of Hofstede's scale, meaning that Israelis are very egalitarian, a worker can generally approach her boss and vice versa (Newman, 1996; Redpath, 1997; Schneider \& Barsoux, 1997).

The affects of PD on IS has been studied by many. Myers and Tan (2002) provide a comprehensive review of various information systems and the effect Hofstede's dimensions were found to have on them. In addition, PD has also been found to affect the design of websites and user interface (UI). Marcus and Gould (2000) show a website of a university in Malaysia (high PD) presents and focuses on power symbols, whereas an equivalent website of a Dutch university (low PD) focuses on the students and displays the ways with which they are empowered. For example, it offers a virtual tour on campus using a WebCam. 
In terms of IS usage, the use of information and communication technology (ICT) for interpersonal communication can be interpreted in different ways by the different cultures. A culture such as Malaysia, which holds a high power distance index in its organisation, could benefit from the introduction of ICT as communication means.

As email communication is perceived as less intrusive (Kraut \& Attewell, 1997), the use of ICT could promote inter-rank communication. However, negative social effects from the use of email as a communication tool, despite individual effort, training and technological development (Markus, 1994) could mitigate the affect. Exploratory research would provide further insight into this matter.

More egalitarian cultures, such as Australia, could experience the opposite if forced to use ICT for inter-rank communication. Communication via ICT might be perceived as a more distant and therefore less favourable. This view is supported by Ali, Pascoe and Warne (2002), as participants in their study of an organizational culture in Australia preferred person-to-person contact to technology-facilitated contact. Since Australia holds a low PD, the same results would apply for communication with supervisors.

\section{Individualism-Collectivism (IC)}

This scale is a measure of whether people prefer to work alone or in groups. It indicates the degree of social/community integration. Indigenous nations tend to be collective where the original culture has not become fractured. USA measures the lowest on this scale, that is, they prefer singular achievement. This comes from a cultural upbringing that expects people to be independent at a very early age. On the other hand, Guatemala ranks the highest meaning that they work in groups and ascribe performance as a cooperative achievement. The lifestyle of a Guatemalan is likely to be based around close family ties with strong community support (Redpath, 1997; Schneider \& Barsoux, 1997; Smith, 1998).

Promoting collaboration is one of the major goals of IS. Tools such as intranet, online forums, shared drives and Group Support Systems (GSS) are some of the tools supporting collaborative activity. They provide means for knowledge sharing, reuse and dissemination. They facilitate group discussion and decision making, and assist with actors' networking. Within Hofstede's framework of cultures it is possible that individualist cultures would resist these efforts of collaborative support, and integrative cultures would adopt them more easily. Conversely, it is possible that the development of such collaborative information systems is more vigorously developed in individualist societies, whereas integrative societies do not require additional support.

Tung and Quaddus (2002) provide a comprehensive review of the differences in use of GSS by various cultures. From this review, it is clear that culture plays a role in the use of GSS, due to PD (discussed below) and IC. For example, Mexican groups (low in individualism) were found to generate a higher level of consensus than US groups (high in individualism) (McGrath \& Hollingshead, 1993). Watson, Ho and Raman (1994) found Singaporean groups (low in individualism) had a higher pre-meeting consensus to US groups (high in individualism). Another perspective on the role of individualism is the contribution to discussions by various researchers. Tan, Wei, Watson, Clapper, and McLean (1998) found participants in Singaporean culture were less likely to challenge majority sayings than participants from US. This indicates that while GSS provides technology for group discussions, cultural influences need to be taken into account. Anonymity has been found to support individual contributions (Ho, Raman \& Watson, 1989). 


\section{Masculinity-Femininity (MF)}

This scale does not refer, absolutely, to the dominance of gender. It depicts the degree to which masculine traits like authority, assertiveness, performance and success are preferred to female characteristics like personal relationships, quality of life, service and welfare. Japan ranks the lowest on Hofstede's scale showing that they are highly paternally oriented. Japanese workplaces are likely to be autocratic. At the other extreme Hofstede found Sweden and Norway. People in these two countries are likely to show more empathy for their fellow workers, they are likely to spend time on relationships and personal ties (Schneider \& Barsoux, 1997; Smith, 1998).

An interpretation of a "paternal" approach towards IS management could be a controlled, centralised approach. Centralisation entails a top-down approach to standards, architecture, settings and processes. In contrast, the accommodation for individual locations and business areas enabled by the flexibility of decentralised IS could be considered "feminine".

Kankanhalli, Tan, Wei and Holmes (2004) take a different view on the operationalisation of masculinity. They characterise "masculine" developers as outcome and process oriented, while "feminine" developers are more concerned with long term relationships. They suggest training to bring "feminine" developers closer to "masculine" ones. However, relationships have been shown to promote trust (Levin and Cross 2004) and knowledge sharing (Hansen, 1999), which in turn benefits organisational performance (Argote, 1999; Argote \& Ingram, 2000; Baum \& Ingram, 1998). Therefore, it seems "feminine" workers make a significant contribution to organizations.

\section{Uncertainty Avoidance (UA)}

UA is the extent to which people are threatened by a lack of structure or by uncertain events. It refers to the way that people will deal with the future, whether they have inherent control, or whether events are beyond their control (fatalism). People with low UA will require structure and order with clear rules and guidelines. Hofstede found Greece to have the lowest UA score. Therefore, people in Greece will be reluctant to make decisions and they will require very structured work routines. Swedes on the other hand can work well without structure and will have a high tolerance for ambiguity (Newman, 1996; Redpath, 1997; Schneider \& Barsoux, 1997; Smith, 1998).

Steensma, Marino, Weaver, and Dickson (2000) found UA plays a role in how small firms form technology alliances. Small companies deal with two types of uncertainty: relational uncertainty, derived from the risk of partnering, and technological uncertainty, derived from the risks involved in technology itself. Steensma et al. (2000) found that firms from high UA ("uncertaintyavoiding") are more likely to pursue technology alliances to avoid uncertainty. Firms from low UA ("uncertainty-tolerant") were more likely to address the risks of uncertainty without the formation of a technological alliance.

UA has been shown to influence the planning and implementation of Enterprise Resource Planning (ERP) (Shanks, Parr, Hu, Corbitt et al., 2000). In a comparative study of US and Chinese implementation of ERP, Shanks et al. (2000) found more planning and attention to detail in the Chinese company. More emphasis was put on data accuracy in the new ERP system by the Chinese company. The writers suggested the reason was not necessarily culturally based, but rather due to previous experiences with problematic data. However, the role of culture cannot be excluded.

In a study of technology acceptance model (TAM) across cultures, Straub, Keil, and Brenner (1997) found UA differentiates between how different cultures accept new information technology. This study shows TAM explains technology acceptance within cultures such as Sweden and 
U.S., but not the Japanese culture. UA is not the only difference in index between the three cultures. Straub et al (1997) provide an explanation that involves UA, PD, IC and MF.

Dependency on IS brings another dimension of uncertainty and risk. Possible threats are theft, loss, corruption of data, destruction, and denial of service (Ciampa, 2005). Consequences involve loss of availability, legal liability and financial losses. These can be detrimental to the organization's survival (Ciampa, 2005). All these risks can be mitigated, but a cost is associated with this mitigation. It is expected that businesses with low tolerance for risk would invest more in the mitigation of these processes. Further research on how the various cultures address such threats could provide additional insight.

While these four dimensions, originally elucidated by Hofstede, provide researchers and practitioners a practical means of identifying and dealing with cultural differences in the context of information systems. Hofstede's schema is not the only analytical framework available, as well, it is not necessarily the best. It is introduced here to provide a glimpse of the potential influences that culture can play in this global environment. In addition, while various cultural differences are explicated here, culture may not be the only reason for these differences. More research is needed in all of these areas to determine causal effects more decisively.

\section{Arguments against Hofstede}

Criticised and complemented on the breadth, depth and import of his study into culture ("Culture's Consequences") Hofstede's work has been nothing short of highly controversial. Like some of the great economists (Keynes, Malthus, Philips) Hofstede is not without his protagonists and antagonists. Many arguments run against Hofstede's work, the discussion that follows endeavours to capture some of the more pertinent issues.

\section{Instrument Utility}

Many researchers allude a survey is not an appropriate instrument for accurately determining and measuring cultural disparity. This is especially apparent when the variable being measured is a value that is culturally sensitive and subjective (McSweeney, 2002; Schwartz, 1999). Hofstede addresses this criticism saying that surveys are one method, but not the only method that was used (Hofstede, 1998).

\section{Cultural Homogeneity}

This criticism is perhaps the most popular. Hofstede's study assumes that national domestic population is a homogenous whole. However, most nations are groups of ethnic units (McSweeney 2002; Myers \& Tan, 2002; Nasif et al., 1991; Redpath, 1997). Canada provides a good illustration of this with its dichotomies of French and English speaking cultures (Straub et al., 2002). Analysis is therefore constrained by the character of the individual being assessed; the outcomes have a possibility of arbitrariness. On the other hand Hofstede tends to ignore the importance of community, and the variations of the community influences (Dorfman \& Howell, 1988; Lindell \& Arvonen, 1996; Smith, 1998).

\section{National Divisions}

Nations are not the proper units of analysis as cultures are not necessarily bounded by borders (McSweeney, 2000). Recent research has found that culture is in fact fragmented across group and national lines (DiMaggio, 1997; Myers \& Tan, 2002), one only needs consider cross-border influences of Arabic cultures to see this weakness (Straub et al., 2002). Hofstede points out how- 
ever that national identities are the only means we have of identifying and measuring cultural differences (Hofstede, 1998, 2002). Further Markus and Soh (2002) explain that even when cultures are similar there are other factors that may influence individual action. For instance, in their study they found that Singapore and China were similarly defined according to Hofstede, but these countries differed markedly in areas of structure (eg: financial infrastructure, legal systems, space and logistics, telecommunications infrastructure, firm structure, industry concentration). They found that cultural divisions based on national criteria were not enough to "provide adequate insight into how ... and why e-commerce activity differs in various parts of the world. For that one also needs an understanding of structural factors" (Markus \& Soh, 2002, p. 10).

\section{Political Influences}

The outcomes, particularly those pertaining to Masculinity (Søndergaard, 1994) and Uncertainty Avoidance (Newman, 1996), may have been sensitive to the timing of the survey. Europe was in the midst of the cold war and was still haunted by vivid memories of World War II; similarly there was the communist insurgence in Asia, Africa and Europe. As a result of the political instabilities of the time, the sample lacks data from socialist countries, as well as from the less affluent Third World Countries.

\section{One Company Approach}

A study fixated on only one company cannot possibly provide information on the entire cultural system of a country (Graves, 1986; McSweeney, 2002; Olie, 1995; Søndergaard, 1994). Hofstede said he was not making an absolute measure, he was merely gauging differences between cultures and this style of cross-sectional analysis was appropriate (Hofstede, 1998, p. 481). In addition, Hofstede points out that the use of a single multinational employer eliminates the effect of the corporate policy and management practices from different companies influencing behaviour differently, leaving only national culture to explain cultural difference (Hofstede, 1980).

\section{Out-dated}

Some researchers have claimed that the study is too old to be of any modern value, particularly with today's rapidly changing global environments, internationalisation and convergence.

Hofstede countered saying that the cross-cultural outcomes were based on centuries of indoctrination, recent replications have supported the fact that culture will not change overnight (Hofstede, 1998, 2002).

\section{Too Few Dimensions}

Four or five dimensions do not give sufficient information about cultural differences. Hofstede agrees, he believes additional dimensions should continue to be added to his original work (Hofstede, 1998, 2002).

\section{Statistical Integrity}

Dorfman and Howell (1988) have found that in his analysis, Hofstede has, on occasion, used the same questionnaire item on more than one scale, and several have significant cross-loadings. In fact, when closely observed, the analysis comprises 32 questions with only 40 cases or subjects (40 data points corresponding to 40 countries). An analysis built on so few 'subjects' takes great advantage of chance and increases the likelihood of sample error (Dorfman \& Howell, 1988, p. 130; Furrer, 2000). 


\section{Arguments in Support of Hofstede}

While the criticisms may be sound, Hofstede's research is one of the most widely used pieces of research among scholars and practitioners, it has many appealing attributes (Furrer, 2000, p. 358; Ross, 1999, p. 14; Søndergaard, 1994). Søndergaard (1994) found that Hofstede's 1980 study received 1,036 citations, while another highly regarded study on strategy by Miles and Snow received only 200 citations. Many researchers agree on the following points which reinforce the value of the study.

\section{Relevance}

During the time of its delivery there was very little work on culture, and at this time many businesses were just entering the international arena and were experiencing difficulties; they were crying out for credible advice. Hofstede's work met and exceeded this demand for guidance. Scholarly attention was also turning toward culture during this period, and Hofstede was considered a pioneer and pathfinder (Søndergaard, 1994, pp. 448-449).

\section{Rigour}

The research framework used by Hofstede was based on rigorous design with systematic data collection and coherent theory. This is just what scholars and the marketplace had been asking for (Søndergaard, 1994, pp. 448-449). However, many critics claim the sampling was flawed, being sparse and unevenly distributed (McSweeney, 2000). McSweeney (2002) finds that the average number of questionnaires used by Hofstede varied per country, with a low average, and "for some countries it was miniscule" (p. 94).

\section{Relative Accuracy}

In Søndergaard's bibliographical analysis (1994) he compared the replications (research similar to Hofstede's IBM study, originated to compare his findings) of Hofstede's research. 61 replications were analysed. The majority of the replications confirmed Hofstede's predictions. Four of the replications concurred in their entirety, and 15 showed partial confirmation. The only dimension of Hofstede's that could not be validly confirmed was 'Individualism', however, Hofstede addressed this issue by predicting that cultures will shift over time (Søndergaard, 1994, pp. 450453).

Several studies were developed not as replications, but along similar lines, to test the relevancy of Hofstede's questions. These have also confirmed the accuracy of Hofstede's four dimensions (Søndergaard, 1994, p. 453).

\section{Recommendations for Further Research}

Culture is one area of social science that receives constant attention. As Søndergaard (1994) found in his research; many researchers have replicated Hofstede's study and many more continue with other cross-cultural studies. However, although Hofstede does not agree (Hofstede, 1998, p. 481), many researchers find culture to be a dynamic, constantly changing field. Cultures are merging, information technology is changing the way we communicate, and globalisation is placing greater demands on IS. Therefore, researchers must keep abreast of these changes to ensure practitioners are provided the best and latest tools ensuring global cooperation. More research is needed to evaluate culture in terms of contemporary standards. Research is also needed to better explore the dimensions proposed by Hofstede and Hofstede and Bond to determine 
whether more can be added, and to determine a solid and indisputable set of cultural factors which will assist the design, development and management of Information Systems.

\section{Conclusion}

This paper has provided an evaluation of Geert Hofstede's ground-breaking work on cross cultural differences. It has included argument in support of Hofstede as well as against his work. While the level of controversy surrounding this work is still quite high, it remains the most valuable piece of work on culture for both scholars and practitioners.

Work on cultural dimensions is not yet complete, the overview of culture that is provided here illustrates the importance of culture, and the impact that each of Hofstede's dimensions has on IS design, development and management. In light of this, system design needs to accommodate the cultural variances that exist around the world to provide a more homogenous solution.

To conclude, more research is needed to capture the shifting cultural maps which are influenced by, and influence, globalisation and information technology. However, this is difficult to achieve and may have temporal value. As a result the work of Hofstede will continue to have value now and into the future.

\section{References}

Ali, I., Pascoe, C. \& Warne, L. (2002). Interactions of organizational culture and collaboration in working and learning. IEEE Journal Educational Technology \& Society, 5(2).

Argote, L. (1999). Organizational learning: Creating, retaining, and transferring knowledge. Boston, Kluwer Academic.

Argote, L. \& Ingram, P. (2000). Knowledge transfer: a basis for competitive advantage in firms. Organizational Behavior and Human Decision Processes, 82(1), 150-169.

Bartels, R. (1967). A Model for Ethics in Marketing. Journal of Marketing, 31(1), 20-26.

Baum, J. \& Ingram, P. (1998). Survival-enhancing learning in the Manhattan hotel industry, 1898-1980. Management Science, 44(7), 996-1016.

Bhagat, R. S. \& McQuaid, S. J. (1982). Role of subjective culture in organizations: A review and directions for future research. Journal of Applied Psychology, 67(5), 653-685.

Bond, M. H. (2002). Reclaiming the individual from Hofstede's ecological analysis- A 20-year odyssey: comment on Oyserman et al. (2002). Psychological Bulletin, 128(1), 73-77.

Cavusgil, S. T. \& Das, A. (1997). Methodology issues in cross-cultural sourcing research - A primer. Marketing Intelligence \& Planning, 15(5), 213.

Ciampa, M. (2005). Security + guide to network security fundamentals. Thomson/Course Technology.

d'Iribarne, P. (1996). The usefulness of an ethnographic approach to the international comparison of organizations. International Studies of Management \& Organization, 26(4), 30.

DiMaggio, P. (1997). Culture and cognition. Annual Review of Sociology, 23(1), 263-287.

Dorfman, P. W. \& Howell, J. P. (1988). Dimensions of national culture and effective leadership patterns: Hofstede revisited. Advances in International Comparative Management, 3, 127-150.

Furrer, O. (2000). The relationships between culture and service quality perceptions: Basis for crosscultural market segmentation and resource allocation. Journal of Service Research [JSR], 2(4), 355.

Graves, D. (1986). Corporate culture - Diagnosis and change: Auditing and changing the culture of organizations. London: Frances Printer. 
Hansen, M. (1999). The search-transfer problem: The role of weak ties in sharing knowledge across organization subunits. Administrative Science Quarterly, 44(1), 82-111.

Hays, R. D., Anderson, R. \& Revicki, D. (1993). Psychometric considerations in evaluating health-related quality of life measures. Quality of Life Research, 2(6), 441-449.

Henry, G. T. (1990). Practical sampling. Newbury Park, Sage Publications.

Ho, T. H., Raman, K. S. \& Watson, R. T. (1989). Group decision support systems: The cultural factor. Proceedings of the Tenth International Conference on Information Systems, 119-129.

Hofstede, G. (1980). Culture's consequences: International differences in work related values. Beverly Hill, CA: Sage.

Hofstede, G. (1991a). Culture and organisations. New York: McGraw-Hill.

Hofstede, G. (1991b). Cultures and organizations: Software of the mind. London: McGraw-Hill.

Hofstede, G. (1997). The Archimedes effect. Working at the interface of cultures: 18 lives in social science. M. H. Bond. London, Routledge: 47-61.

Hofstede, G. (1998). Attitudes, Values and Organizational Culture: Disentangling the concepts. Organization Studies, 19(3), 477.

Hofstede, G. (2002). Dimensions do not exist: A reply to Brendan McSweeney. Human relations, 55(11), $1355-1361$.

Hofstede, G. \& Bond, M. H. (1984). Hofstede's culture dimensions: An independent validation using Rokeach's value survey. Journal of Cross-Cultural Psychology, 15(4), 417-433

Hofstede, G. \& Bond, M. H. (1988). The Confucius connection: From cultural roots to economic growth. Organizational Dynamics, 16(4), 5-21.

Johnson, T. P. (1998). Approaches to equivalence in cross-cultural and cross-national survey research. ZUMA Nachrichten Spezial, 3, 1-40.

Kankanhalli, A., B. Tan, C. Y., Wei, K. K. \& Holmes, M. C. (2004). Cross-cultural differences and information systems developer values. Decision Support Systems, 38(2), 183-195.

Kraut, R. \& Attewell, H. (1997). Media use in a global corporation electronic mail and organizational knowledge. Research milestones on the information highway. S. Kiesler, Mahwah, Nk Erlbaum.

Kumar, K. \& Bjorn-Anderson, N. (1990). A cross-cultural comparison of IS designer values. Information Systems, 33(5), 528-538.

Levin, D. \& Cross, R. (2004). The strength of weak ties you can trust: The mediating role of trust in effective knowledge transfer. Management Science, 50(11), 1477-1490.

Lindell, M. \& Arvonen, J. (1996). The Nordic management style in a European context. International Studies of Management \& Organization, 26(3), 73.

Lubrosky, L. (1959). Psychotherapy. Annual Review of Psychology, 10(1), 317-344.

Markus, M. L. (1994). Finding a happy medium: Explaining the negative effects of electronic communication on social life at work. ACM Transactions on Information Systems (TOIS), 12(2), 119-149.

Markus, M. L. \& Soh, C. (2002). Structural influences on global e-commerce activity. Journal of Global Information Management, 10(1), 5-12.

Martin, J. \& Frost, P. J. (1996). The organizational culture war games: A struggle for intellectual dominance. In S. R. Clegg, C. Hardy \& W. R. Nord (Eds.), The handbook of organization studies (pp. 599621). Thousand Oaks, CA: Sage.

McGrath, J. E. \& Hollingshead, A. B. (1993). Groups interacting with technology: Ideas, evidence, issues and an agenda. Thousand Oaks, CA, USA: Sage Publications. 
McSweeney, B. (2000). The fallacy of national culture identification. 6th Interdisciplinary Perspectives on Accounting Conference, Manchester, UK.

McSweeney, B. (2000). Hofstede's model of national cultural differences and their consequences: A triumph of faith - a failure of analysis. Human Relations, 55(1), 89-118.

Michael, J. (1997). A conceptual framework for aligning managerial behaviors with cultural work values. International Journal of Commerce \& Management, 7(3/4), 81.

Myers, M. D. \& Tan, F. B. (1997). Beyond models of national culture in information systems research. Journal of Global Information Management, 10(1), 24-32.

Nasif, E. G., Al-Daeaj, H., Ebrahimi, B. \& Thibodeaux, M. S. (1991). Methodological problems in crosscultural research: An update. Management International Review, 31(1), 79.

Newman, K. L. (1996). Culture and congruence: The fit between management practices and national culture. Journal of International Business Studies, 27(4), 753.

Olie, R. (1995). The 'culture' factor in personnel and organization policies. In A. Harzing \& V. R. J. London, International Human Resource Management: An integrated approach (pp. 124-143). Sage Publications.

Peters, T. J. \& Waterman, R. H. J. (1982). In search of excellence. New York: Harper \& Row.

Redpath, L. (1997). A comparison of native culture, non-native culture and new management ideology. Revue Canadienne des Sciences de l'Administration, 14(3), 327.

Ross, D. N. (1999). Culture as a context for multinational business: A framework for assessing the strategyculture 'fit'. Multinational Business Review, 7(1), 13.

Schneider, S. C. \& Barsoux, J.-L. (1997). Managing across cultures. Europe: Prentice Hall.

Schwartz, S. H. (1999). A theory of cultural values and some implications for work. Applied Psychology, 48(1), 23-47.

Shanks, G., Parr, A., Hu, B., Corbitt, B., Thanasankit, T. \& Seddon, P. (2000). Differences in critical success factors in ERP systems implementation in Australia and China: A cultural analysis. Proceedings of the European Conference on Information Systems, 537-544.

Smith, M. (1998). Culture and organisational change. Management Accounting, 76(7), 60.

Søndergaard, M. (1994). Hofstede's consequences: A study of reviews, citations and replications. Organization Studies, 15(3), 447.

Steensma, H. K., Marino, L., Weaver, K. M., \& Dickson, P. H. (2000). The influence of national culture on the formation of technology alliances by entrepreneurial firms. The Academy of Management Journal, 43(5), 951-973.

Straub, D., Keil, M., \& Brenner, W. (1997). Testing the technology acceptance model across cultures: A three country study. Information \& Management, 33(1), 1-11.

Straub, D., Loch, K., Evaristo, R., Karahanna, E. \& Strite, M. (2002). Toward a theory-based measurement of culture. Journal of Global Information Management, 10(1), 13-23.

Tan, B. C. Y., Wei, K. K., Watson, R. T., Clapper, D. L. \& McLean, E. R. (1998). Computer-mediated communication and majority influence: Assessing the impact in an individualistic and a collectivistic culture. Management Science, 44(9), 1263-1278.

Tung, L. L. \& Quaddus, M. A. (2002). Cultural differences explaining the differences in results in GSS: implications for the next decade. Decision Support Systems, 33(2), 177-199.

Watson, R. T., Ho, T. H. \& Raman, K. S. (1994). Culture: a fourth dimension of group support systems. Communications of the ACM, 37(10), 44-55. 
Zahir, S. (2002). Cross-cultural dimensions of Internet portals Sajjad Zahir, Brian Dobing, M. Gordon Hunter The Authors. Internet Research: Electronic Networking Applications and Policy, 12(3), 210220.

\section{Biographies}

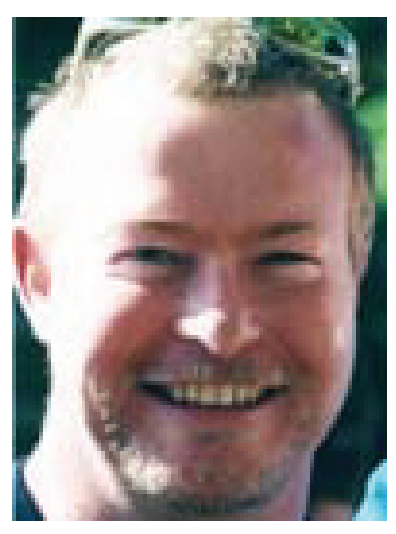

Michael Jones (BComm (hons), PhD.) has been an academic teaching and researching in areas of organisation, business and management for eight years. Michael has developed research interests in the following areas: organisational psychology and behaviour - looking at commitment and motivation and group dynamics. Michael is also developing research strengths in areas of qualitative analysis and has written several papers on various qualitative methodologies and methods. Michael is also interested in research areas such as knowledge management and organisational learning. Michael is also a co-investigator on a major research project explore competitive analysis in the Australian Marine Industry.

Michael is a member of the Australia and New Zealand Academy of Management, the Australian Human Resources Institute, and the Industrial Relations Society of Australia.

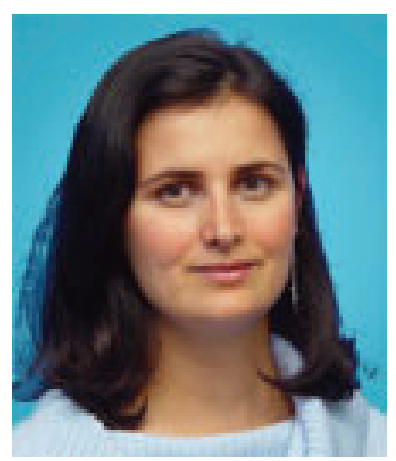

Irit Alony (BCSc; Grad.Cert. (Comp Sc.); MIS) has been an academic teaching and researching in areas of information systems, knowledge management, and communication and culture for two years at Central Queensland University. Irit has developed research interests in the following areas: knowledge sharing, tacit knowledge, creative industries, knowledge management and strategic use of information systems. Irit is also developing research strengths in areas of qualitative analysis. Irit is involved in a major research project exploring competitive analysis in the Australian Marine Industry.

Irit is currently engaged in the early stages of her $\mathrm{PhD}$ researching knowledge sharing. 